Special Issue of the 6th International Congress \& Exhibition (APMAS2016), Maslak, Istanbul, Turkey, June 1-3, 2016

\title{
Comparison of Naturally and Synthetically Derived Hydroxyapatite Powders
}

\begin{abstract}
A. Yelten* AND S. YilmaZ
Istanbul University, Department of Metallurgical and Materials Engineering, 34320 Istanbul, Turkey

Hydroxyapatite (HA) constitutes the mineral component of the hard tissues such as bone and teeth. HA is a bioactive ceramic material and can form biochemical bonds with tissues. It is possible to produce HA powders either from natural sources or by using synthetic chemicals. Wet chemical precipitation technique is an ideal method to practically and economically synthesize HA powders. Calcium hydroxide $\left(\mathrm{Ca}(\mathrm{OH})_{2}\right)$ and ortho-phosphoric acid $\left(\mathrm{H}_{3} \mathrm{PO}_{4}\right)$ solutions were used as the calcium and phosphorus sources to obtain the HA powders. Acid-alkaline reactions between starting materials were carried out at three different reaction temperatures (room temperature, $50-60^{\circ} \mathrm{C}$ range and $70-80^{\circ} \mathrm{C}$ range) which may affect the microstructure of the produced powders. The procedure of HA powders preparation from natural sources consists of several steps: in the order of deproteinization of bovine bones in $\mathrm{NaOH}$, washing the deproteinized bovine bones, calcination of the washed bones, and grinding the calcined bones, respectively. In this study, HA powders derived from bovine bones and HA powders obtained through the wet chemical precipitation method were compared in terms of their chemical, microstructural and molecular bonding properties by applying various characterization techniques such as X-ray diffraction, scanning electron microscope-energy dispersive spectroscopy, and the Fourier transform infrared spectroscopy.
\end{abstract}

DOI: 10.12693/APhysPolA.131.55

PACS/topics: $81.20 . \mathrm{Fw}$

\section{Introduction}

Hard tissues such as bone and teeth are the main parts of a body besides soft tissues and organs. In case of an injury, damage or loss, it becomes an essential point to repair or renew the tissue. $\mathrm{Ca}_{10}\left(\mathrm{PO}_{4}\right)_{6}(\mathrm{OH})_{2}$ is the chemical formula of HA which is the mineral phase of bone. HA has a hexagonal crystal structure and stands in the hard tissues surrounded by collagen fibers as the organic phase of the bone. HA cannot be used as a single component for load bearing applications due to its brittle structure. However, filling fractures, improving the bioactivity behavior of an inert but strong material, etc. can be defined as the usage areas of HA. Powders, granules, fibers, coatings, etc. are different forms of HA for the biomedical field $[1,2]$.

Hydrothermal method, solid-state reactions, sol-gel process, emulsion and microemulsion techniques are some of the methods that can be applied to produce synthetic HA powders. Among these procedures wet chemical precipitation technique emerges as the most common process to synthesize HA powders owing to its advantages such as being a simple method, requiring inexpensive starting materials and working at low reaction temperatures $[2-7]$. Several parameters influence the results of the acid-alkaline reaction and in this research, acid reactant addition rate and reaction temperature factors were studied. Reaction temperature has a role in determining the resultant particle size and shape of the obtained HA powders while acid addition rate is responsible

\footnotetext{
* corresponding author; e-mail: azade.yelten@istanbul.edu.tr
}

for the well-crystallization and growth of the HA particles [4-8]. Natural sources such as bovine bones, egg shells, coral reefs, etc. can be also employed to obtain HA powders [2, 9-12]. All these structures can be called as natural calcium storage and helped to produce biological apatites. Biological apatite can be simply described as the non-stoichiometric $(\mathrm{Ca} / \mathrm{P}$ molar ratio $\neq 1.67)$ type of HA where Ca deficiency is observed but lack of $\mathrm{Ca}$ is compensated by other elements such as sodium, magnesium, carbon, etc. which are rarely found in the natural matter $[1,2]$. In this study, properties of the naturally derived HA from the bovine bones and wet chemically precipitated HA were investigated and the differences between them were analyzed.

\section{Material and equipment}

Synthetic HA powders were produced through the wet chemical precipitation technique and natural HA powders derived from the bovine bones were provided by Oktar et al. [9]. Experimental procedure of the naturally derived HA powders includes the stages of the order of deproteinization of the bovine bones in $\mathrm{NaOH}$, washing the deproteinized bovine bones, calcination of the deproteinized and washed bovine bones, and finally grinding the calcinated bones in a mortar grinder.

In the wet chemical precipitation technique, $\mathrm{Ca}(\mathrm{OH})_{2}$ (calcium hydroxide, Sigma-Aldrich, ACS reagent, $\geq 95 \%$ ) was used as the calcium source while $\mathrm{H}_{3} \mathrm{PO}_{4}$ (phosphoric acid, Sigma-Aldrich, ACS reagent, $\geq 85 \mathrm{wt} \%$ in $\mathrm{H}_{2} \mathrm{O}$ ) is the phosphorus source [4-8]. Since it is an acid-base process, the experimental procedure relies on adding the acid solution to the alkaline suspension dropwise with a rapid or slow addition rate at three different reaction temperatures, i.e. room temperature, $50-60^{\circ} \mathrm{C}$ and $70-80^{\circ} \mathrm{C}$ for this research. Concentrations of the 
starting material solutions were determined by considering the $\mathrm{Ca} / \mathrm{P}$ molar ratio of the product which is 1.67 for stoichiometric HA and the reaction between the precursors is stated in Eq. (1) [4-8]. The steps that were carried out during the wet chemical precipitation method can be shortly explained as: first, the acid-base reaction between $\mathrm{Ca}(\mathrm{OH})_{2}$ and $\mathrm{H}_{3}\left(\mathrm{PO}_{4}\right)$ at $25^{\circ} \mathrm{C}, 50-60^{\circ} \mathrm{C}$ and $70-80^{\circ} \mathrm{C}$, ageing of the $\mathrm{CaP}$ suspension obtained as a result of the reaction, filtrating the $\mathrm{CaP}$ suspension by employing a Buchner funnel and a vacuum pump, washing the $\mathrm{CaP}$ precipitate with distilled water to remove any possible contamination, drying the CaP filter cake at $110^{\circ} \mathrm{C}$ for $2 \mathrm{~h}$, manually grinding the dried precipitate with a mortar and pestle to have $\mathrm{CaP}$ powders and finally heat treating of the $\mathrm{CaP}$ powders at $900^{\circ} \mathrm{C}$ for $1 \mathrm{~h}$ with a $10^{\circ} \mathrm{C} / \mathrm{min}$ heating rate to achieve well-crystallized $\mathrm{HA}$ powders. The sample codes of the wet chemically precipitated HA powders and the process parameters applied for each sample were shown in Table I. "900" in the sample codes presents the heat treatment temperature $\left({ }^{\circ} \mathrm{C}\right)$ while 25,55 , and 75 stand for the reaction temperature $\left({ }^{\circ} \mathrm{C}\right) . S$ and $R$ display the slow and rapid acid addition rate, respectively,

$$
\begin{aligned}
& 10 \mathrm{Ca}(\mathrm{OH})_{2}+6 \mathrm{H}_{3}\left(\mathrm{PO}_{4}\right) \rightarrow \\
& \mathrm{Ca}_{10}\left(\mathrm{PO}_{4}\right)_{6}(\mathrm{OH})_{2}+18 \mathrm{H}_{2} \mathrm{O} .
\end{aligned}
$$

TABLE I

A summary of the process parameters considered for the wet chemically precipitated HA powder samples.

\begin{tabular}{c|c|c}
\hline \hline Sample code & Acid addition rate & Reaction temperature \\
\hline $900 \mathrm{HA} 25 \mathrm{~S}$ & $\approx 1 \mathrm{drop} / 2-3 \mathrm{~s}$ (slow) & room temp. $25-30^{\circ} \mathrm{C}$ \\
$900 \mathrm{HA} 25 \mathrm{R}$ & $\approx 2 \mathrm{drops} / \mathrm{s}$ (rapid) & room temp. $25-30^{\circ} \mathrm{C}$ \\
$900 \mathrm{HA} 55 \mathrm{~S}$ & $\approx 1 \mathrm{drop} / 2-3 \mathrm{~s}$ (slow) & $50-60^{\circ} \mathrm{C}$ \\
$900 \mathrm{HA} 55 \mathrm{R}$ & $\approx 2 \mathrm{drops} / \mathrm{s}$ (rapid) & $50-60^{\circ} \mathrm{C}$ \\
$900 \mathrm{HA} 75 \mathrm{~S}$ & $\approx 1 \mathrm{drop} / 2-3 \mathrm{~s}$ (slow) & $70-80^{\circ} \mathrm{C}$ \\
$900 \mathrm{HA} 75 \mathrm{R}$ & $\approx 2 \mathrm{drops} / \mathrm{s}$ (rapid) & $70-80^{\circ} \mathrm{C}$
\end{tabular}

Chemical phase determination was performed by X-ray diffraction (XRD) analyses through monochromatic $\mathrm{Cu} K_{\alpha}$ radiation $(\lambda=0.154 \mathrm{~nm})$ at a Rigaku D/Max$2200 /$ PC branded device. The mean crystallite sizes $(D)$ of the powders were calculated using the Scherrer formula [13] given in Eq. (2). In this formula, $\lambda$ is for the wavelength of $\mathrm{Cu} K_{\alpha}, B$ for the full width at half maximum (FWHM) and $\theta$ for the diffraction angle

$$
D=\frac{0.9 \lambda}{B \cos \theta}
$$

Microstructure characterization of the powder samples was realized by using JEOL branded JSM 5600 and JSM $6335 \mathrm{~F}$ model scanning electron microscopes (SEM) and the elemental analyses were conducted with an XRF branded 550I model energy dispersive spectroscopy (EDS) system. All samples were coated with a thin layer of gold before being placed in the SEM. The Fourier transform infrared spectroscopy (FTIR) analyses were done with a Perkin Elmer Spectrum 100 branded device and the $\mathrm{KBr}$ method to study the molecular bonding properties of the HA powders.

\section{Results and discussion}

Figure 1 shows the XRD analyses where all wet chemically precipitated HA samples presented the characteristic peaks of hexagonal synthetic hydroxyapatite (HA, syn, $\left(\mathrm{Ca}_{5}\left(\mathrm{PO}_{4}\right)_{3}(\mathrm{OH})\right)$ phase with powder diffraction files (PDF) number 09-432. These results were also confirmed from several researches in literature $[5,6,14,15]$ and the major peaks of the HA phase were marked on the XRD spectrum. For the 900HA75S and 900HA75R samples, peaks of the Whitlockite $\left(\mathrm{Ca}_{3}\left(\mathrm{PO}_{4}\right)_{2}\right.$, $\mathrm{PDF}$ number 09-0169) phase were also observed. Since the solubility of $\mathrm{Ca}(\mathrm{OH})_{2}$ decreases with the increase of temperature [8], it is thought that this situation affects the complete precipitation of the $\mathrm{HA}$ phase at the temperature range of $70-80{ }^{\circ} \mathrm{C}$ and leads to an amount of $\mathrm{Ca}_{3}\left(\mathrm{PO}_{4}\right)_{2}$ existing in the structure. Crystallite sizes were calculated as $58.637 \mathrm{~nm}$ for $900 \mathrm{HA} 25 \mathrm{~S}, 21.212 \mathrm{~nm}$ for $900 \mathrm{HA} 25 \mathrm{R}$, $103.307 \mathrm{~nm}$ for $900 \mathrm{HA} 55 \mathrm{~S}$ and $74.484 \mathrm{~nm}$ for 900HA55R. It is clearly realized that the crystallite sizes of the HA powders synthesized at room temperature are smaller than the samples produced at $50-60^{\circ} \mathrm{C}$. Similarly, the crystallite sizes of the powders obtained under slow acid addition rate condition are larger than the ones precipitated by applying a rapid acid addition rate. As the acidalkaline reaction temperature increased, larger crystallites formed and the peaks in the XRD spectra became narrower and sharper so that the crystallinity improved. Moreover, slow acid addition rate lets the acid-alkaline reaction to develop in a longer period of time and allows the crystallites to finely nucleate and grow [8]. However, for the high reaction temperatures, i.e. $70-80^{\circ} \mathrm{C}$, it was not possible to make a distinct comment on the crystallite size of the HA powders again due to insufficient solubility of the $\mathrm{Ca}(\mathrm{OH})_{2}$ phase.

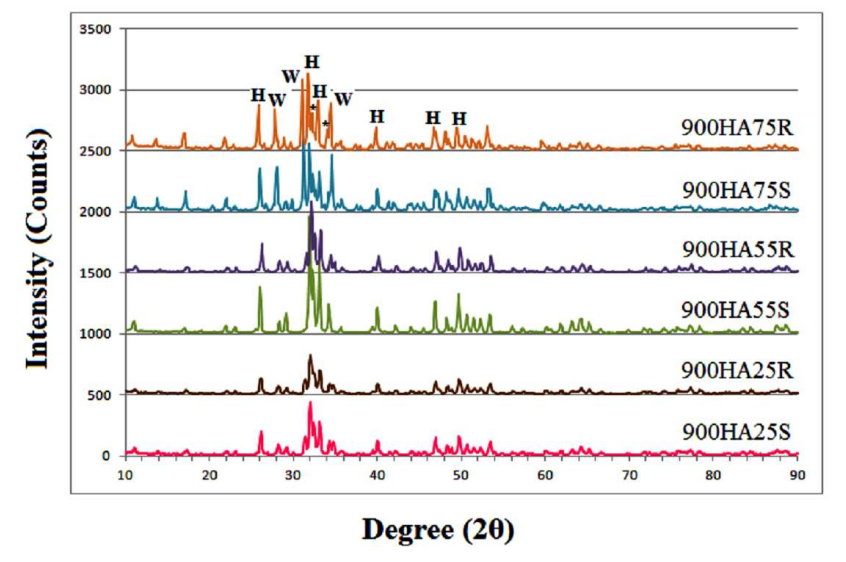

Fig. 1. XRD results of the wet chemically precipitated HA powders (H and $*$ for hydroxyapatite (PDF 09-432); $\mathrm{W}$ for whitlockite (PDF 09-0169)).

Figure 2 displays the FTIR analyses of the wet chemically precipitated HA powders. FTIR results enabled the investigation of the chemical bonding characteristics of the synthesized powders. First, the small peak at 


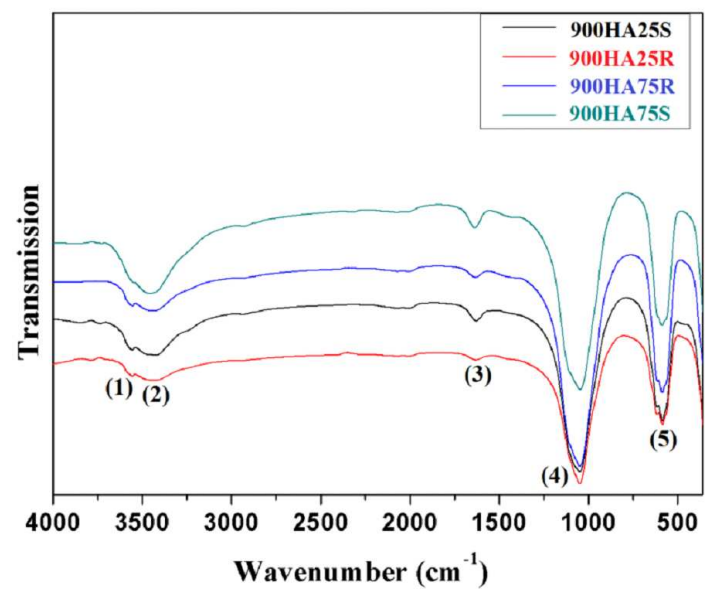

Fig. 2. FTIR results of the 900HA25S, 900HA25R, 900HA75S, and 900HA75R powder samples.

$3570 \mathrm{~cm}^{-1}$ was attributed to the $\mathrm{OH}^{-}$ion stretching vibration. The bands at $3500-3265 \mathrm{~cm}^{-1}$ and $1634 \mathrm{~cm}^{-1}$ were referred to adsorbed water. The weak peak at $\approx 1634 \mathrm{~cm}^{-1}$ indicates the $\mathrm{CO}_{3}^{-2}$ ion content which may exist due to carrying out the experimental procedure under air and therefore absorption of $\mathrm{CO}_{2}$ from the atmosphere. The characteristic peak at $1033 \mathrm{~cm}^{-1}$ was assigned to the $\mathrm{P}-\mathrm{O}$ stretching vibrations of the $\mathrm{PO}_{4}^{-3}$ ions while the peaks at 611 and $583 \mathrm{~cm}^{-1}$ arouse from the $\mathrm{P}-\mathrm{O}$ bending vibrations of $\mathrm{PO}_{4}^{3-}$ ions in the HA structure $[6,16-18]$.

Figure $3 \mathrm{a}$ exhibits the XRD and Fig. $3 \mathrm{~b}$ presents the FTIR analysis of the naturally derived HA powders.

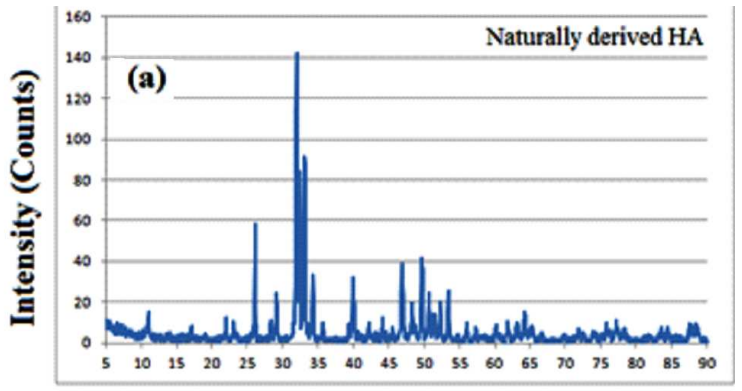

Degree (20)

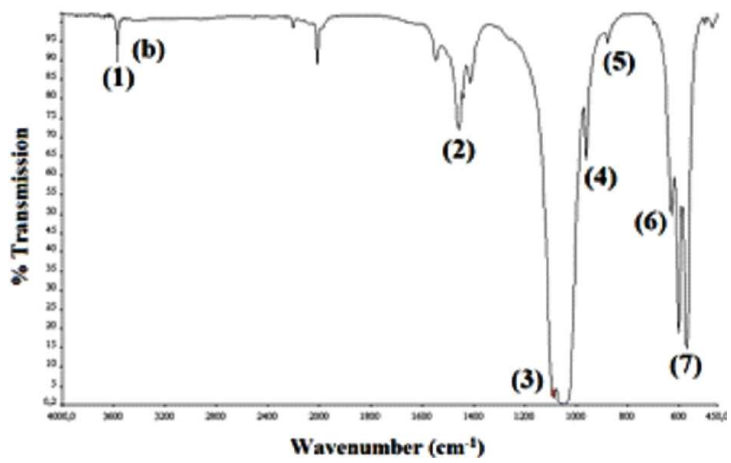

Fig. 3. (a) XRD spectrum (PDF\#74-0566 and PDF \# 84-1998) and (b) FTIR analysis of the naturally derived HA powders.
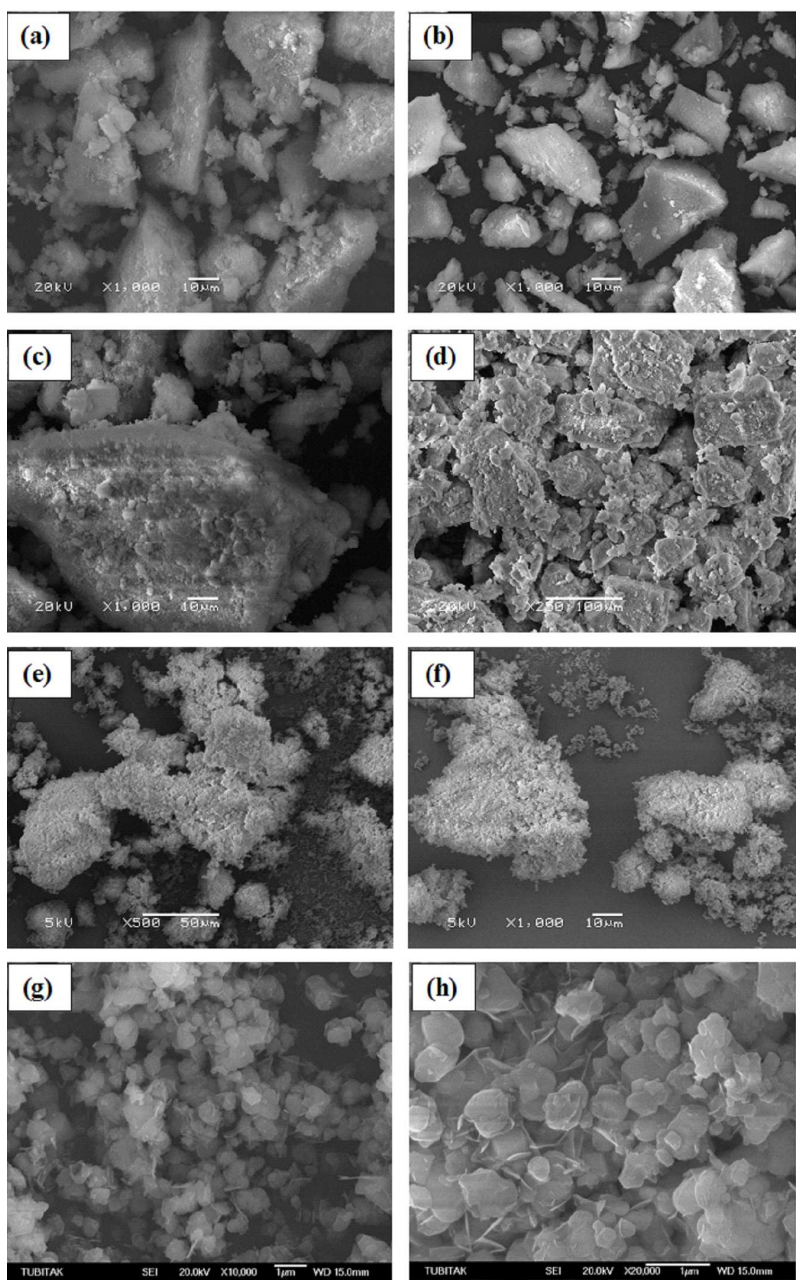

Fig. 4. SEM images of the (a) 900HA25S, (b) $900 \mathrm{HA} 25 \mathrm{R}, \quad$ (c) $900 \mathrm{HA} 55 \mathrm{~S}$, (d) 900HA55R, (e) $900 \mathrm{HA} 75 \mathrm{R}$, (f) $900 \mathrm{HA} 75 \mathrm{~S}$, (g) and (h) naturally derived HA powders.

Hexagonal HA with PDF numbers 74-0566 and 84-1998 is the major phase that was detected in the structure. FTIR spectrum helped to make a comparison about the chemical bonding characteristics between the synthetically precipitated HA powders and the naturally derived ones. First, the sharp peak at $3571 \mathrm{~cm}^{-1}$ was attributed to the $\mathrm{OH}^{-}$ion stretching vibration. Structural $\mathrm{OH}^{-}$ion vibrations of the HA phase were also seen at $631 \mathrm{~cm}^{-1}$. Three clear peaks observed at 1546, 1457, and $1412 \mathrm{~cm}^{-1}$ indicate the stretching vibrations of the $\mathrm{CO}_{3}^{-2}$ ions while the smaller peak at $879 \mathrm{~cm}^{-1}$ represents the vibrations of the $\mathrm{CO}_{3}^{-2}$ ions which replace with the other ions in the HA lattice due to the usage of bovine bones. The characteristic peaks at 1089,1053 , and $962 \mathrm{~cm}^{-1}$ were assigned to the $\mathrm{P}-\mathrm{O}$ stretching vibrations of the $\mathrm{PO}_{4}^{-3}$ ions in $\mathrm{HA}$. The peaks at 602 and $571 \mathrm{~cm}^{-1}$ arouse from the $\mathrm{P}-\mathrm{O}$ bending vibrations of $\mathrm{PO}_{4}^{3-}$ ions in the HA structure $[6,16-18]$.

SEM images of the wet chemically precipitated HA powders in Fig. 4a-f revealed that the powders have a high 
tendency to agglomerate. Agglomerates with different sizes were observed in the structure which is an expected case since the wet chemical precipitation technique relies on the nucleation-aggregation-agglomeration-growth mechanism $[7,8]$. Naturally derived HA powders exhibited flat, plate-like particle morphology (Fig. $4 \mathrm{~g}$ and $\mathrm{h}$ ). No agglomerations were seen and the powders were composed of pretty thin plates. All EDS analyses indicated that $\mathrm{Ca}, \mathrm{P}$, and $\mathrm{O}$ elements exist in the structure but the $(\mathrm{Ca} / \mathrm{P})$ molar ratio was calculated not directly as 1.67 but close to it for most of the wet chemically precipitated samples. However, for the naturally derived HA powders, this ratio inevitably changes owing to other elements that may be already found in the bovine bone structure.

\section{Conclusion}

Some important facts about this research can be summarized as:

- Chemical, microstructural, and molecular bonding properties of the synthetic HA powders produced through the wet chemical precipitation technique and natural HA powders derived from the bovine bones were investigated.

- In the wet chemical precipitation technique, $\mathrm{Ca}(\mathrm{OH})_{2}$ was used as the calcium source while $\mathrm{H}_{3} \mathrm{PO}_{4}$ is the phosphorus source and all precipitated HA samples presented the characteristic peaks of synthetic HA $\left(\mathrm{Ca}_{5}\left(\mathrm{PO}_{4}\right)_{3}(\mathrm{OH})\right)$ phase. For the 900HA75S and 900HA75R samples, peaks of the whitlockite $\left(\mathrm{Ca}_{3}\left(\mathrm{PO}_{4}\right)_{2}\right)$ phase were also observed. Hexagonal HA with PDF numbers 74-0566 and 841998 is the major phase that was detected in the naturally derived HA powders.

- The crystallite sizes of the powders obtained under high reaction temperature $\left(50-60^{\circ} \mathrm{C}\right)$ and slow acid addition rate conditions are larger than the ones precipitated under room temperature and rapid acid addition rate conditions.

- Adsorbed water bands and characteristic peaks of the $\mathrm{OH}^{-}, \mathrm{PO}_{4}^{-3}$ and $\mathrm{CO}_{3}^{-2}$ ions were detected from the FTIR spectra.

- SEM images of the wet chemically precipitated HA powders revealed that the powders have a high tendency to agglomerate while naturally derived HA powders have a plate-like particle shape.

\section{Acknowledgments}

The authors would like to thank the Research Fund (BAP) (grant no. 37881) and Teaching Staff Training Program Office (ÖYP) of Istanbul University for providing financial support to this project.

\section{References}

[1] B.D. Ratner, A.S. Hoffman, F.J. Schoen, J.E. Lemons, Biomaterials Science. An Introduction to $\mathrm{Ma}$ terials in Medicine, 2nd ed., Elsevier Academic Press, New York 2004, pp. 1, 162.

[2] A. Yelten, M.Sc. Thesis, Istanbul University, 2010.

[3] S. Cox, Synthesis Method of Hydroxyapatite.

[4] K. Salma, L. Berzina-Cimdina, N. Borodajenko, Process. Appl. Ceram. 4, 45 (2010).

[5] A. Paz, D. Guadarrama, M. Lopez, J.E. Gonzales, N. Brizuela, J. Aragon, Quim. Nova 35, 1724 (2012).

[6] S.S.A. Abidi, Q. Murtaza, J. Mater. Sci. Technol. 30, 307 (2014).

[7] M.H. Santos, M. de Oliveira, L.P. de Freitas Souza, H.S. Mansur, W.L. Vasconcelos, Mater. Res. 7, 625 (2004).

[8] S. Kehoe, Ph.D. Thesis, Dublin City University, 2008.

[9] F.N. Oktar, S. Agathopoulos, L.S. Ozyegin, O. Gunduz, N. Demirkol, Y. Bozkurt, S.S. Salman, J. Mater. Sci. Mater. Med. 18, 2137 (2007).

[10] C.Y. Ooi, M. Hamdi, S. Ramesh, Ceram. Int. 33, 1171 (2007).

[11] C. Balazsi, F. Weber, Z. Kover, E. Horvath, C. Nemeth, J. Eur. Ceram. Soc. 27, 1601 (2007).

[12] A. Yelten, S. Yilmaz, F.N. Oktar, Ceram. Int. 38, 2659 (2012).

[13] B.D. Cullity, Elements of X-Ray Diffraction, 2nd ed., Addison-Wesley, USA 1978, p. 102.

[14] L.B. Kong, J. Ma, F. Boey, J. Mater. Sci. 37, 1131 (2002).

[15] Y. Liu, D. Hou, G. Wang, Mater. Chem. Phys. 86, 69 (2004).

[16] R. Kumar, K.H. Prakash, P. Cheang, K.A. Khor, Langmuir 20, 5196 (2004).

[17] I. Rehman, W. Bonfield, J. Mater. Sci. Mater. Med. 8, 1 (1997).

[18] A. Chandrasekar, S. Sagadevan, A. Dakshnamoorthy, Int. J. Phys. Sci. 8, 1639 (2013). 